\title{
The effect of metal ions on the reaction of hydrogen peroxide with Kraft lignin model compounds
}

\author{
Yujun Sun, Michael Fenster, Annie Yu, Richard M. Berry, \\ and Dimitris S. Argyropoulos
}

\begin{abstract}
Peroxide bleaching is significantly affected by transition and alkaline earth metals. Isolating the effects of different transition and alkaline earth metals on the reactions of peroxide with different representative lignin structures allows the separation of the positive from the negative contributions of these metal ions. In this work, five monomeric or dimeric phenolic lignin model compounds were treated with alkaline hydrogen peroxide in the absence or presence of $\mathrm{Mn}^{2+}, \mathrm{Cu}^{2+}, \mathrm{Fe}^{3+}$, and $\mathrm{Mg}^{2+}$. We followed the disappearance of the starting material and the progress of demethylation, radical coupling and oxalic acid formation were followed. Transition metals increased the reactivities of all the lignin model compounds with hydrogen peroxide in the order $\mathrm{Mn}^{2+}>\mathrm{Cu}^{2+}>\mathrm{Fe}^{3+}$, which is the same as the order of activity toward peroxide decomposition while $\mathrm{Mg}^{2+}$ stabilized the system. Demethylation, radical coupling, and oxalic acid formation were all increased by the presence of transition metals in the system and decreased by the addition of $\mathrm{Mg}^{2+}$. The acceleration of the total degree of reaction and of the demethoxylation reactions improves peroxide bleaching, but the increase in the radical coupling reactions can affect the further bleachability of pulp while the increase in the formation of oxalic acid could lead to a greater probability of scaling.
\end{abstract}

Key words: lignins, hydrogen peroxide, peroxide bleaching, reactivity, chemical pulps, metal compounds, alkali treatment, transition metals, delignification.

Résumé : Le blanchiment au peroxyde est affecté d'une façon significative par les métaux de transition et alcalinoterreux. En isolant les effets des divers métaux de transition et alcalinoterreux sur les réactions du peroxyde avec diverses structures représentatives de lignine, on peut séparer les contributions positives et négatives de ces ions métalliques. Dans ce travail, cinq composés modèles de lignine phénolique monomère ou dimère ont été traités par du peroxyde d'hydrogène en milieu alcalin, en présence ou en l'absence de $\mathrm{Mn}^{2+}, \mathrm{Cu}^{2+}, \mathrm{Fe}^{3+}$ et $\mathrm{Mg}^{2+}$. On a suivi la disparition du produit de départ et le progrès de la déméthylation, du couplage radicalaire ainsi que de la formation d'acide oxalique. Les métaux de transition augmentent les réactivités de tous les composés modèles de la lignine avec le peroxyde d'hydrogène et l'ordre de cet effet est $\mathrm{Mn}^{2+}>\mathrm{Cu}^{2+}>\mathrm{Fe}^{3+}$, le même que celui de l'ordre d'activité vis-à-

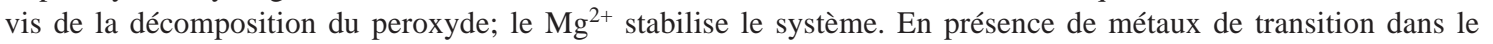
système, les vitesses de déméthylation, de couplage radicalaire et de formation d'acide oxalique sont toutes augmentées; l'addition de $\mathrm{Mg}^{2+}$ les diminue. L'accélération du degré total de réaction et des réactions de déméthoxylation améliore le blanchiment au peroxyde, mais l'augmentation des réactions de couplage radicalaire peut éventuellement affecter la possibilité de pousser le blanchiment de la pulpe alors que l'augmentation de la formation d'acide oxalique peut éventuellement conduire à une plus grande probabilité de d'encrassement.

Mots clés : lignines, peroxyde d’hydrogène, blanchiment par le peroxyde, réactivité, pulpes chimiques, composés métalliques, traitement alcalin, métaux de transition, délignification.

[Traduit par la Rédaction]

Received November 11, 1998.

This paper is dedicated to Jerry Kresge in recognition of his many achievements in chemistry.

Y. Sun and D.S. Argyropoulos. ${ }^{1}$ PAPRICAN and Department of Chemistry, Pulp and Paper Research Centre, McGill University, 3420 University St., Montreal, PQ H3A 2A7, Canada.

R.M. Berry. PAPRICAN, McGill University, 3420 University St., Montreal, PQ H3A 2A7, Canada.

M. Fenster and A. Yu. Department of Chemistry, Pulp and Paper Research Centre, McGill University, 3420 University St., Montreal, PQ H3A 2A7, Canada.

${ }^{1}$ Author to whom correspondence may be addressed. Telephone: (514) 398-6178. Fax: (514) 398-8254.

e-mail: dimitria@shared1.lan.mcgill.ca 
<smiles>Cc1ccc(O)c(O)c1</smiles><smiles>COc1cc(C)ccc1O</smiles>

Catechol (1)
Creosol (2)

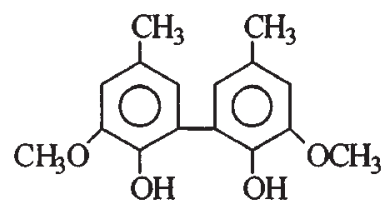

5-5' Dimer (3)<smiles>COc1cc(Cc2ccc(C)cc2O)ccc1O</smiles>

$\alpha-5^{\prime}$ Dimer (4)<smiles>COc1cc(C)cc(Cc2cc(C)cc(OC)c2O)c1O</smiles>

5-CH2-5' Dimer (5)

\section{Introduction}

Hydrogen peroxide interacts with lignin via two different sets of reactions; perhydroxyl anions nucleophilically attack and eliminate lignin chromophores, while free radical species, formed through the decomposition of hydrogen peroxide, cause the oxidative degradation of phenolic lignin structures converting them to carboxylic acids (1). Freeradical species have also been claimed to participate in chromophore elimination reactions (2-5). During hydrogen peroxide bleaching of chemical pulps, the presence of transition metal ions and in particular manganese, copper, and iron is known to catalyze peroxide decomposition. In contrast, magnesium is known to stabilize peroxide. In the absence of transition metal ions, the decomposition of hydrogen peroxide proceeds via a homogeneous, $\mathrm{pH}$ dependent, bimolecular reaction involving hydroperoxy anions $(6,7)$. Earlier efforts aimed at revealing the reaction details between lignin model compounds and alkaline hydrogen peroxide in the absence of transition metal ions have shown that hydrogen peroxide degrades phenolic units to low molecular weight aliphatic carboxylic acids (8-14). However, Gierer and Imsgard (15) have shown that phenolic units are stable to alkaline peroxide but are reactive to hydroxy radicals arising from the decomposition of hydrogen peroxide. Abbot et al. $(6,7,16)$ have also demonstrated that differences exist in the catalytic action of manganese, copper, iron, and magnesium ions toward peroxide decomposition in the presence and absence of pulp. Despite the fact that chelation and even an acid wash is frequently used to remove the transition metal ions from the pulp prior to bleaching, it is undeniable that traces of such species still remain in the system contributing to the complexity of the reaction sequences. The large variety of highly reactive species present in such reactions coupled with the complex structural features of residual Kraft lignin has made it difficult to define the interaction of alkaline peroxide with residual Kraft lignin and transition metal ions.

The continued international effort toward implementing environmentally benign bleaching sequences, which now often include pressurized $(17,18)$ and high-temperature $(19$, 20) peroxide warrants closer attention to be paid at the fundamentals of the reactions of alkaline hydrogen peroxide with residual Kraft lignins and its model compounds. Residual Kraft lignin contains significant amounts of condensed structures such as 5-5', $\alpha-5$, diphenylmethane, and stilbene units (21-23). Despite such structures being abundant in residual Kraft lignin, to date there have been no studies dealing with their reactions with alkaline hydrogen peroxide and the effect of transition metals in such a system. The aim of this work is to evaluate the reactivity of residual Kraft lignin moieties with alkaline hydrogen peroxide in the presence and absence of transition metals. In particular, a series of model compounds representing typical structures found in residual Kraft lignin were allowed to react with alkaline hydrogen peroxide in the presence and absence of manganese, iron, copper, and magnesium ions.

\section{Experimental}

\section{Materials}

The model compounds used during this investigation were 4-methylcatechol (1), 3-methoxy-4-hydroxytoluene or creosol (2), the condensed dimer containing a 5-5' linkage (3), the condensed dimer containing an $\alpha-5$ linkage (4), and the condensed dimer containing a methylene linkage (5). Catechol (1) and creosol (2) were purchased from Aldrich Chemicals and used without further purification. Model compounds 3, $\mathbf{4}$, and $\mathbf{5}$ were synthesized following literature procedures $(24,25)$. Hydrogen peroxide $(30 \%)$ and magnesium sulfate (98.0\%) were purchased from ACP Chemicals, and iron(III) sulfate $(97.0 \%)$, sodium hydroxide of semiconductor purity (99.99\%) were purchased from Aldrich Chemical Co. Copper(II) sulfate (98.4\%) was purchased from Baker Chemicals, while manganese sulfate $(99.8 \%)$ was purchased from Fisher Scientific Co. The remaining reagents and solvents were of analytical grade or better. The water used in this study was first distilled and then passed through a nanopure analytical deionization system (Barnstead).

\section{Reactions of model compounds with peroxide}

The precise reagent stoichiometry was established by considering a benzene ring as one unit. As such the ratio of model compound/peroxide/ $\mathrm{NaOH}$ was $1 / 3 / 2$ (on molar basis) for mononuclear models 1 and 2 and 1/6/4 for dinuclear models 3, 4, and 5. The concentration of metal ions used during this study was $0.5 \%$ for compounds $\mathbf{1}$ and $\mathbf{2}$ and $1 \%$ for compounds $\mathbf{3}, \mathbf{4}$, and $\mathbf{5}$. This concentration was in excess of the solubility limit of the hydroxides under the alkaline conditions used in this work. Therefore, the metal ions present should be considered as being present as their hydrous oxide precipitates in equilibrium with the oxidation mixture.

The model compound (100 mg) was mixed with a known volume of deionized water, never exceeding $20 \mathrm{~mL}$. The $\mathrm{pH}$ was adjusted to 12 by adding a predetermined amount of $1 \mathrm{~N} \mathrm{NaOH}$, and then the solution of the metal ion $(0.01 \mathrm{~N})$ was added. Hydrogen peroxide was then added using a $100 \mathrm{~mL}$ syringe. Finally, the total volume was made up to $25 \mathrm{~mL}$ with water. All reactions were carried out in stainless steel bombs equipped with a glass liner immersed in a hot water bath maintained at $80^{\circ} \mathrm{C}$ for $2 \mathrm{~h}$. 
Table 1. The calculated $\mathrm{H}_{2} \mathrm{O}_{2}$ consumption (\%) and the general product profiles as obtained using quantitative GC analyses for the treatment of various model compounds with alkaline peroxide in the presence or absence of metal ions.

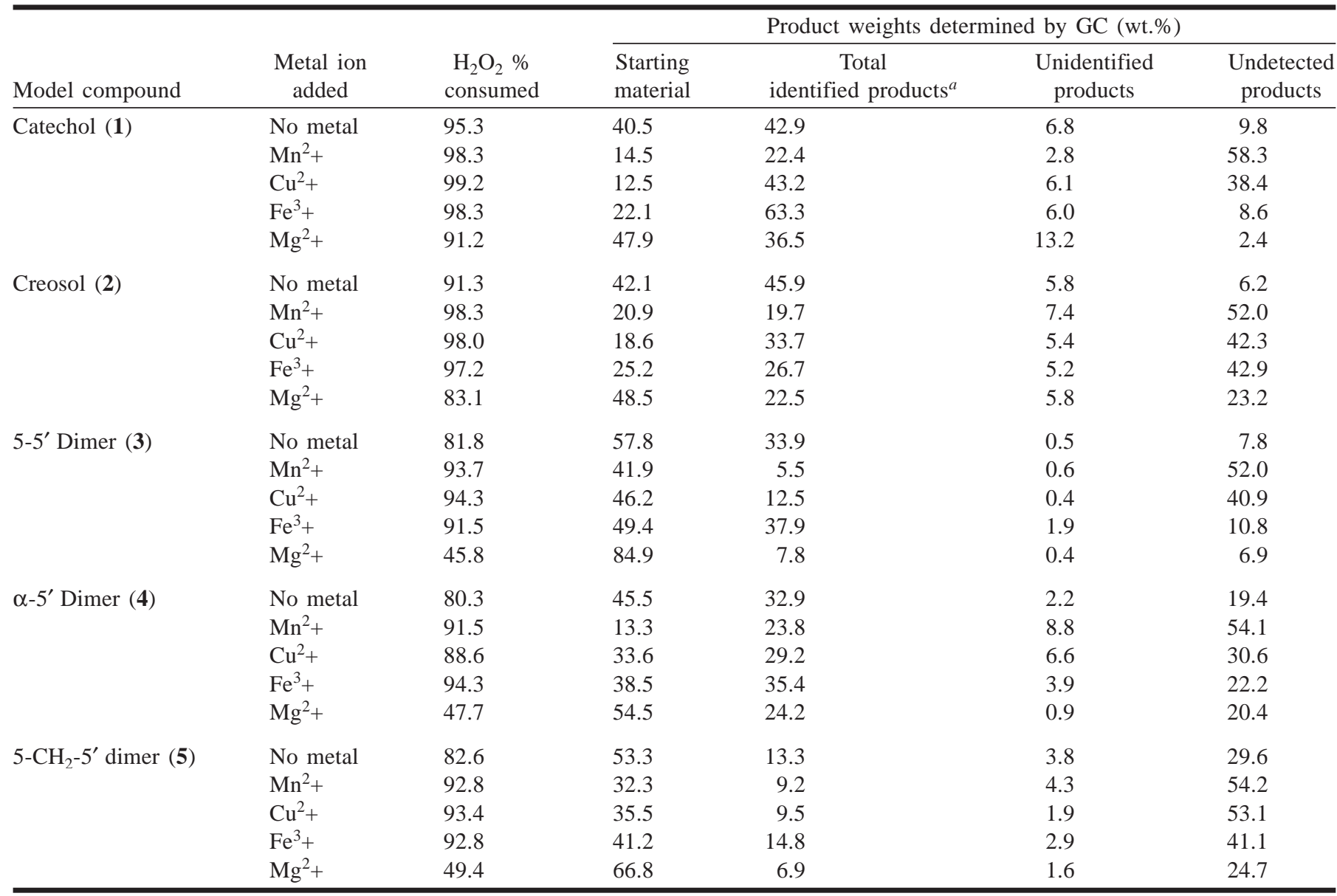

${ }^{a}$ Total identified products excluding starting material.

\section{Reaction work-up procedure}

At the end of the reaction a $2.0 \mathrm{~mL}$ aliquot of reaction mixture was withdrawn, and the concentration of residual peroxide was determined using an iodometric titration. The $\mathrm{pH}$ of the reaction mixtures was then adjusted to 2 using $10 \% \mathrm{HCl}$, and the acidified mixture was extracted with ethyl acetate $(3 \times 50 \mathrm{~mL})$ and chloroform $(3 \times 50 \mathrm{~mL})$. The organic extracts were stirred over anhydrous magnesium sulfate, filtered, and concentrated using a rotary evaporator with the water bath set at $25^{\circ} \mathrm{C}$. The aqueous phase was freeze-dried, and the resulting solid was extracted with acetone. The extracts from the organic and aqueous phases were combined, dried at room temperature, and subjected to GC/MS analyses. The $\mathrm{H}_{2} \mathrm{O}_{2}$ consumption data and reaction yields are tabulated in Table 1.

\section{Analytical methods}

GC/MS analyses were carried out on a Hewlett Packard 5972 mass spectrometer interfaced to a Hewlett Packard 5890-A gas chromatograph equipped with a DB-5 $30 \mathrm{~m} \times$ $0.25 \mathrm{~mm}$ packed silica capillary column. The injection port temperature was $280^{\circ} \mathrm{C}$, and the oven temperature was raised from 70 to $250^{\circ} \mathrm{C}$ with a gradient of $15^{\circ} \mathrm{C} / \mathrm{min}$. The products were analyzed after being silylated using N,Obis(trimethylsilyl)acetamide. The compounds were identified by comparing their fragmentation patterns with those of commercially available or independently synthesized authentic samples.

Product quantification was carried out by using a gas chromatograph coupled to a flame ionization detector under conditions identical to those described previously. The product ratios were evaluated by using 4-methoxyphenol as the internal chromatographic standard. The GC response factors relative to the standard were determined using one of two methods. For commercially available compounds, their response factors were obtained by mixing known volumes of the compound with standard solutions, followed by GC area measurements. For compounds that were not available, their relative response factors were calculated by using the Effective Carbon Number (ECN) concept $(26,27)$. The contributions to ECN for specific functional groups are shown in Appendix.

The major MS fragmentation patterns for trimethylsilylated compounds discussed in this work are as follows: $-m / z$ (relative intensity \%): product 1: $268(\mathrm{M}, 35 \%), 253(6)$, 180(10), 165(6), 149(6), 73(100); 1.01: 219 (M - 15, 3\%), 190(5), 147(81), 133(4), 73(100); 1.02: 233 (M - 15, 30\%), 147(100), 117(23), 73(45); 1.03: 260 (M, 9\%), 245(4), 147(29), 143(79), 73(100); 1.04: 356 (M, 26\%), 341(2), 267(50), 179(40), 147(15), 73(100); 1.05: 534 (M, 16\%), 
343(7), 305(8), 205(8), 147(10), 73(100); 2: 210 (M, 24), 195(14), 180(100), 165(8), 149(8), 73(13); 2.02: 205 (M 15, 12), 177(9), 147(81), 73(100); 2.03: 261 (M - 15, 7\%), 186(3), 147(100), 129(7), 73(79); 2.04: 259 (M - 15, 9\%), 184(4), 147(100), 97(8), 73(41); 2.06: 418 (M, 37\%), 403(16), 388(23), 314(4), 287(8), 179(6), 165(3), 73(100); 2.07: $476(\mathrm{M}, 15 \%), 461(2), 358(13), 299(4), 207(3)$, 179(4), 147(8), 73(100); 2.08: 346(43\%), 331(29), 316(56), 287(15), 241(47), 213(13), 165(11), 147(11), 73(100); 2.09: 404 (M, 46\%), 389(11), 374(13), 300(8), 193(21), 73(100); 3.03: 238 (M, 5\%), 223(100), 208(34), 179(8), 165(7), 151(7), 73(14); 3.04: 311 (M - 15, 75\%), 281(8), 238(10), 207(11), 179(11), 151(12), 133(14), 73(100); 3.05: 436 (M, 4\%), 305(100), 215(4), 188(6), 115(5), 73(39); 4: 418 (M, 100\%), 403(35), 388(79), 373(10), 358(23), 193(8), 179(14), 73(74); 4.02: 247 (M - 15, 15\%), 147(100), 73(73); 4.03: 245 (M - 15, 100\%), 147(58), 143(17), 115(9), 73(98); 4.06: 335 (M - 15, 7\%), 245(13), 233(24), 147(63), 133(10), 73(100); 4.07: 312 (M, 67\%), 297(100), 282(35), 267(64), 253(41), 223(53), 193(20), 126(24), 73(76); 4.08: 396 (M, 25\%), 338(34), 308(11), 209(90), 179(40), 147(9), 73(100); 4.09: 346 (M, 20\%) 331(12), 316(48), 301(16), 241(13), 179(13), 115(11), 73(100); 5: 432 (M, 68\%), 417(27), 402(35), 329(8), 299(7), 193(16), 179(7), 73(100); 5.03: 490 $(\mathrm{M}, 16 \%), 475(3), 372(15), 360(9), 195(19), 180(13)$, 147(6), 73(100); 5.04: 410 (M, 17\%), 352(6), 277(15), 220(11), 208(13), 193(31), 147(19), 73(100); 5.05: 450 (M, 17\%), 435(14), 390(10), 243(14), 217(10), 251(26), 147(11), 73(100); 5.06: 538 (M, 3\%), 404(17), 263(32), 231(29), 147(14), 73(100).

\section{Results and discussion}

Table 1 shows the $\mathrm{H}_{2} \mathrm{O}_{2}$ consumption, the total amounts of identified products (excluding any remaining starting materials), the amounts of unidentified compounds, and those that could not be detected by GC. The yields of products recovered after the reaction varied between 67 and $92 \%$. Severe degradation of model compounds with the formation of volatile and highly water soluble products likely accounts for the unrecovered material.

\section{Effect of metal ions on the reactivity of hydrogen peroxide with residual Kraft lignin model compounds}

The mechanism of alkaline hydrogen peroxide delignification of chemical pulps is complicated due to the complexity of the lignin structure and the large variety of reactive species formed during the process. Figures $1 a$ and $1 b$ display the reactivities of the examined lignin model compounds toward alkaline $\mathrm{H}_{2} \mathrm{O}_{2}$ in the presence or absence of metal ions. By presenting the same data in different ways, two sets of evaluations and comparisons can be made: one addressing the reactivity of the various lignin models in the presence (or absence) of the same metal ion (Fig. 1a) and the other the influence of the various metal ions on the same model compound (Fig. 1b).

The plots of Fig. 1a show that, in general, the reactivities of the five model compounds examined was of the following order: catechol (1) $>$ creosol (2) $>\alpha-5^{\prime}$ dimer (4) $>5-\mathrm{CH}_{2}-5^{\prime}$ dimer (5) $>5-5^{\prime}$ dimer (3). This reactivity order is what one would expect by considering the degree of activation caused
Fig. 1. The reactivity (reflected by the amount of remaining starting material) of the various residual Kraft lignin model compounds examined during this work, in the presence and absence of various metal ions: $(a)$ displays the data as a function of the individual metal ions added; $(b)$ displays the data as a function of the individual model compounds examined.
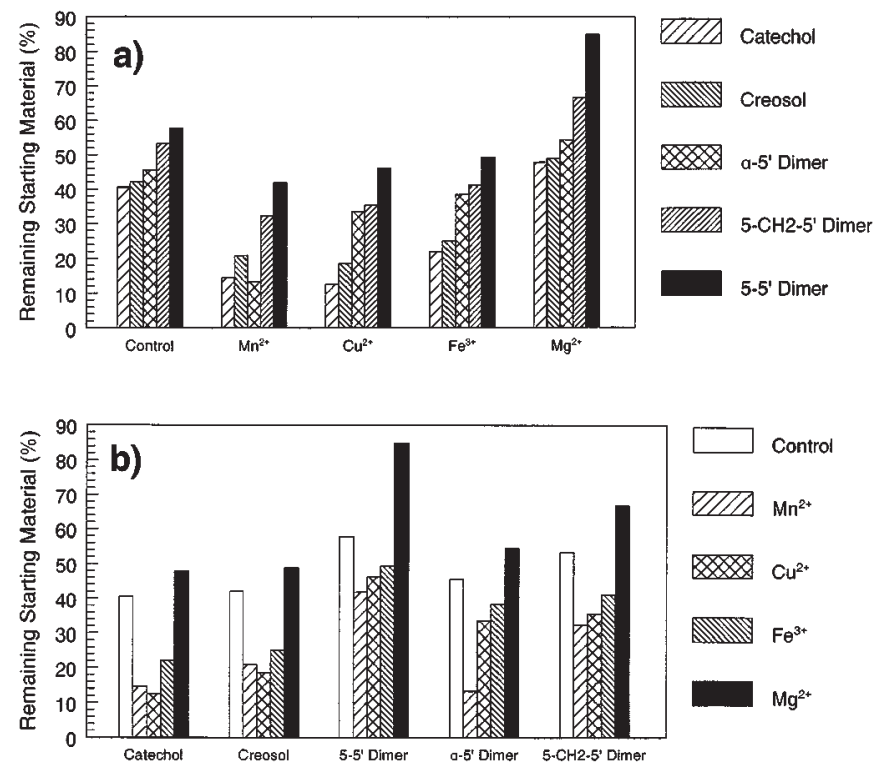

by the groups present on the aromatic rings, i.e., $\mathrm{OH}>$ $\mathrm{OCH}_{3}>\mathrm{CH}_{3}>\mathrm{C}_{6} \mathrm{C}_{5}$. The high reactivity of catechol moieties is in accord with the finding of Francis and Reeve (28). Our data also show that the more activated the aromatic structure, the greater its reactivity toward alkaline hydrogen peroxide, irrespective of the metal ion being added. The presence of metal ions did not significantly alter the above reactivity order but did change the extent of reactions.

Johansson and Ljunggren (29) have demonstrated, using model compounds, that during oxygen delignification the presence of two phenolic hydroxyl groups on an aromatic ring considerably increases its reactivity toward oxygen; methylcatechol was found to be more reactive than creosol. In addition, Johansson and Ljunggren (29) have shown that the reactivity of a mononuclear aromatic structure is greater than its dinuclear analogue. Similarly, using critical oxidation potential data, Kratzl et al. (30) have arrived at the same conclusions. In these respects, our findings are in complete agreement with the literature claims despite different systems having been examined. Since hydroxyl and superoxide anion radicals are the two major radical species produced from the stepwise reduction of oxygen and from the decomposition of hydrogen peroxide (31) and since these radicals are more reactive toward phenolic compounds than peroxide or oxygen, it is not surprising that the data that emerges from the present study parallels the mechanistic information already described for oxygen delignification.

Compared to our control runs, the addition of metal ions dramatically affected the reactivities of the examined model compounds toward alkaline hydrogen peroxide (Fig. 1b). The transition metals increased the extent of reaction between hydrogen peroxide and the model compounds, as evidenced by the decreased amounts of remaining starting material present after the reaction (compared to the control). 
The presence of magnesium ions, however, protected all model compounds from being decomposed as evidenced by the increase of the remaining starting material (Fig. 1b).

Of the transition metals evaluated in most cases, the manganese ions caused the greatest increase in reactivity, while iron caused the least. The range of reactivity was particularly large for the dinuclear model compounds. Similar conclusions describing the effect of these ions toward decomposing peroxide have appeared in the literature (16, 32). Smith and McDonough (33) have demonstrated that the oxidation of compound $\mathbf{5}$ and the decomposition of peroxide was aided by transition metals in the following order: $\mathrm{Mn}^{2+}$ $>\mathrm{Cu}^{2+}>\mathrm{Fe}^{3+}$, their results being somewhat different at longer reaction times.

Our data are also in agreement with the speculation of Brown and Abbot (16) that transition metals decompose peroxide with the subsequent formation of a number of reactive species and that these species in turn react with lignin considerably faster than alkaline peroxide itself. The transition metals can also affect the reactivity of alkaline peroxide with phenolic moieties in lignin. Transition metal ions such as $\mathrm{Mn}^{2+}, \mathrm{Cu}^{2+}$, and $\mathrm{Fe}^{3+}$ may act as electron acceptors catalyzing phenoxy radical formation. The formation of such radicals is thought to be the rate-determining step in the oxidation of phenols, with copper ions being particularly effective $(33,34)$. This increase in reactivity caused by copper ions is seen in this present work. Catechol $\mathbf{1}$ and creosol 2 were oxidized more efficiently in the presence of copper ions than in the presence of any other metals (Fig. 1b).

The mechanism of action of magnesium salts in peroxide and oxygen delignification has been the subject of considerable literature discussions (7, 32, 35-37). In general, magnesium ions are thought to stabilize alkaline hydrogen peroxide either by deactivating the transition metals, by forming protective Mg-metal complexes around them (37), or by stabilizing superoxide anion radicals via the formation of stable magnesium superoxide complexes, thereby disrupting freeradical chain decomposition reactions (32). The stabilizing action of magnesium ions is clearly reflected in the data of Fig. $1 b$, since in its presence, the reactivity of all model compounds with alkaline hydrogen peroxide was significantly reduced.

\section{Radical coupling reactions}

Literature accounts have documented that aqueous hydrogen peroxide decomposes to yield molecular oxygen and water via various free-radical intermediates, particularly when the process is catalyzed by transition metal ions (38, 39), i.e.,

$$
\begin{aligned}
& \mathrm{H}_{2} \mathrm{O}_{2}+\mathrm{OH}^{-} \leftrightarrow \mathrm{HO}_{2}^{-}+\mathrm{H}_{2} \mathrm{O} \\
& \mathrm{H}_{2} \mathrm{O}_{2}+\mathrm{HO}_{2}^{-} \rightarrow \mathrm{HO}^{-}+\mathrm{O}_{2}^{--}+\mathrm{H}_{2} \mathrm{O} \\
& \mathrm{HO}+\mathrm{O}_{2}^{--} \rightarrow \mathrm{OH}^{-}+\mathrm{O}_{2}
\end{aligned}
$$

The various radical species formed interact with phenolic compounds, giving rise to phenoxyl radicals, which then become involved in coupling and (or) rearrangement reactions. Gierer et al. (40) who have examined the detailed chemistry that operates between lignin model compounds and hydroxyl radicals have arrived at the conclusion that under alkaline conditions coupling is the dominant reaction.

In an effort to examine the role of the different transition metal ions in inducing the formation of radical coupling products in phenolic residual Kraft lignin moieties, particular attention was paid to accurately quantifying the fraction of products which were of high molecular weight. Such compounds could not be volatilized and consequently could not be detected by gas chromatography. To these values the amount of identified and (or) rearranged products was then added, yielding the total amount of radical coupling products formed. More specifically, the following identified products (Table 2) were considered the result of radical coupling reactions: for compound 1: 1.05; for compound 2: 2.06-2.09; for compound 3: 3.05, 3.06; for compound 4: 4.09; for compound 5: 5.05 and 5.06.

The data of Fig. 2 show that of transition metal ions induced the formation of considerable amounts of coupling products. Manganese ions caused the highest formation of radical coupling products for all examined model structures.

Of the three transition metal ions examined in this effort, $\mathrm{Fe}^{3+}$ ions were found to generate the least amount of radical coupling products. This is consistent with the data of Landucci (34) who reported that, in alkaline media, $\mathrm{Fe}^{3+}$ ions cannot abstract an electron from a phenol or a phenolate anion. The beneficial effects of $\mathrm{Mg}^{2+}$ ions are once again apparent in the data of Fig. 2. The presence of $\mathrm{Mg}^{2+}$ significantly reduced the amount of radical coupling products being formed, except for creosol, which was also particularly sensitive to all of the transition metals.

In summary, the data presented in this section suggest that the negative effects of transition metals in peroxide bleaching are not only due to peroxide decomposition reactions which reduce its efficiency, but also to the formation of stable structures through radical coupling reactions which also make residual Kraft lignin harder to oxidize. The radical coupling data of Fig. 2 can explain the relatively poor response of Kraft pulp toward chlorine dioxide after oxygen or peroxide delignification (41). Radical coupling products formed in residual Kraft lignin during an oxygen and a peroxide stage are more susceptible to reaction with chlorine or ozone rather than chlorine dioxide (42). Since the role of magnesium ions in the presence of different transition metal ions has not been addressed in detail, the focus of a subsequent investigation in our laboratory will be precisely this, with emphasis on radical coupling product formation.

\section{Reaction product profiles}

Scheme 1 shows the structures of the main reaction products detected for all examined model compounds, while Table 2 depicts the determined amounts for each product. However, some minor identified products and certain intermediates are not shown. The following discussion will be focused on the effect of the various metal ions on product profiles without delving into the detailed reaction mechanisms responsible for the formation of these products, since such efforts have been adequately covered by other authors $(9,40,43)$.

If the main reactive species during alkaline hydrogen peroxide bleaching was the hydroperoxide anion, enone and carbonyl containing moieties would react while phenolic or 
Table 2. The determined amounts of products formed from the interaction of model compounds $\mathbf{1}-\mathbf{5}$ when treated with alkaline hydrogen peroxide in the presence or absence of various transition metal ions. ${ }^{a}$

\begin{tabular}{|c|c|c|c|c|c|c|c|c|c|c|}
\hline$\frac{\text { Model }}{\text { Catechol (1) }}$ & Metal ion & \multicolumn{9}{|c|}{ Product profiles $(\%)$} \\
\hline & None & 4.4 & 10.6 & 8.2 & 10.7 & 2.8 & & & & \\
\hline & $\mathrm{Cu}^{2}+$ & 16.5 & 7.2 & 8.4 & 5.4 & 3.9 & & & & \\
\hline & $\mathrm{Fe}^{3}+$ & 19.7 & 8.1 & 17.5 & 8.7 & 3.4 & & & & \\
\hline & $\mathrm{Mg}^{2}+$ & 1.6 & 10.0 & 9.3 & 10.3 & 0.5 & & & & \\
\hline \multirow{5}{*}{ Creosol (2) } & None & 2.9 & 2.6 & 16.4 & 14.2 & 0.5 & 0 & 2.6 & 0.5 & 0 \\
\hline & $\mathrm{Mn}^{2}+$ & 5.1 & 1.9 & 1.0 & 0.6 & 3.0 & 1.0 & 5.9 & 3.1 & 1.0 \\
\hline & $\mathrm{Cu}^{2}+$ & 8.0 & 2.1 & 1.4 & 4.3 & 2.9 & 0.7 & 6.3 & 7.2 & 1.4 \\
\hline & $\mathrm{Fe}^{3}+$ & 6.8 & 3.5 & 1.6 & 4.9 & 2.2 & 0.5 & 5.5 & 1.5 & 1.0 \\
\hline & $\mathrm{Mg}^{2}$ & 1.9 & 2.2 & 5.7 & 3.8 & 1.5 & 0.9 & 0.5 & 0 & 0 \\
\hline \multirow{2}{*}{ 5-5' Dimer (3) } & $\mathrm{Fe}^{3}+$ & 2.0 & 2.4 & 1.7 & 29.1 & 1.0 & 1.7 & & & \\
\hline & $\mathrm{Mg}^{2}+$ & 0 & 0 & 2.4 & 5.4 & 0 & 0 & & & \\
\hline \multirow[t]{6}{*}{$\alpha-5^{\prime}$ Dimer (4) } & & 4.01 & 4.02 & 4.03 & 4.04 & 4.05 & 4.06 & 4.07 & 4.08 & 4.09 \\
\hline & None & 6.1 & 3.0 & 4.7 & 1.6 & 4.1 & 9.1 & 0.9 & 0.6 & 2.6 \\
\hline & $\mathrm{Mn}^{2}+$ & 7.8 & 0.6 & 1.1 & 1.0 & 1.4 & 2.6 & 1.0 & 1.5 & 6.6 \\
\hline & $\mathrm{Cu}^{2}+$ & 8.5 & 0 & 4.2 & 2.2 & 2.1 & 4.0 & 0 & 1.2 & 5.3 \\
\hline & $\mathrm{Fe}^{3}+$ & 9.3 & 2.6 & 4.3 & 1 & 4.1 & 6.5 & 1 & 1.7 & 3.5 \\
\hline & $\mathrm{Mg}^{2}+$ & 2.3 & 1.3 & 2.0 & 3.1 & 1.4 & 11.4 & 0.8 & 0.7 & 1.1 \\
\hline \multirow[t]{2}{*}{$5-\mathrm{CH}_{2}-5^{\prime}$ dimer (5) } & & 5.01 & 5.02 & 5.03 & 5.04 & 5.05 & 5.06 & & & \\
\hline & None & 1.5 & 3.9 & 0.5 & 3.0 & 3.9 & 0.5 & & & \\
\hline
\end{tabular}

${ }^{a}$ Product numbering corresponds to the structures shown in Scheme 1.

Fig. 2. The amounts of radical coupling products formed during the reaction of alkaline hydrogen peroxide with various residual Kraft lignin model compounds in the presence or absence of various metal ions.

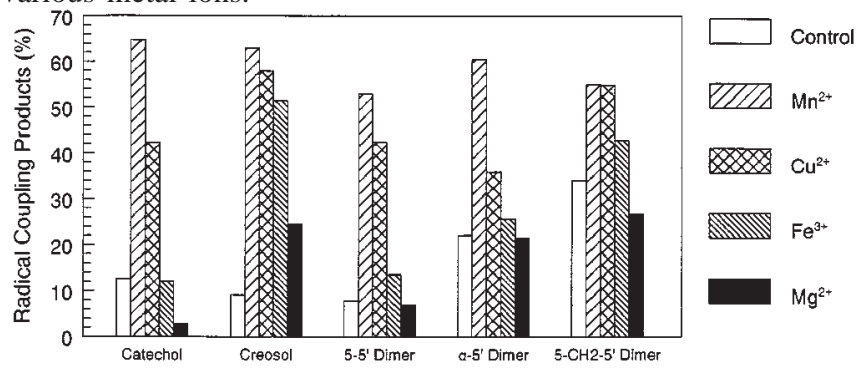

catecholic centres would not (15). The structures of the detected products, however (Scheme 1), show that significant degradation and radical coupling reactions have occurred. Such products are formed from the interaction of the decomposition products of hydrogen peroxide with model compounds $\mathbf{1 - 5}$.

The reaction products detected from the interaction of catechol $\mathbf{1}$ and creosol $\mathbf{2}$ with alkaline hydrogen peroxide in the presence and absence of the various transition metal ions indicate that the primary route for the breakdown of such phenolic moieties consists of ring opening followed by more severe fragmentation (9). In addition, 5-5' and 5-O-4' coupling products were present (products 1.05 and 2.06-2.09) as a consequence of carbon- and oxygen-centred radical coupling reactions. As well, the detected radical coupling products were found to increase in the presence of $\mathrm{Mn}^{2+}, \mathrm{Cu}^{2+}$, and $\mathrm{Fe}^{3+}$ ions (Table 2). Carbon-centred radicals are thought to efficiently recombine, since the resulting dimers have lower critical oxidation potentials (COP) than the original monomers (30).

Oxalic acid (entries 1.01, 2.01, and 4.01; Table 2) is of particular significance to peroxide bleaching operations, since oxalate salts are known to form detrimental deposits on bleach plant process equipment. Table 2 and Fig. 3 show that compounds $\mathbf{1}, \mathbf{2}$, and $\mathbf{4}$ generated a large amount of oxalic acid, and catechol 1 produced the most. The amount of formed oxalic acid increased in the presence of transition metal ions, while the presence of magnesium ions significantly suppressed the formation of oxalic acid, bringing it to levels lower to those of the control experiments. 
Scheme 1. The main identified products obtained from the interaction of model compounds $\mathbf{1}-\mathbf{5}$ when treated with alkaline hydrogen peroxide in the presence and absence of various transition metal ions. The product numbering corresponds to the amounts shown in Table 2.<smiles>CC(=O)C=CC(=O)O</smiles><smiles>Cc1cc(O)c(O)c(-c2cc(C)cc(O)c2O)c1</smiles><smiles>COc1ccc(C)cc1O</smiles><smiles>C/C(=C/C(=O)O)C(=O)O</smiles><smiles>Cc1ccc(O)c(O)c1</smiles><smiles>COc1cc(C)cc(-c2cc(C)cc(OC)c2O)c1O</smiles>

2 2.01

2.02

2.03

2.04

2.05

2.06<smiles>COc1cc(C)cc(-c2cc(C)cc(O)c2O)c1O</smiles>

2.07<smiles>COc1cc(C)ccc1Oc1cc(C)cc(OC)c1O</smiles>

2.08<smiles>COc1cc(C)cc(Oc2ccc(C)cc2O)c1O</smiles>

2.09<smiles>COc1cc(C)cc(-c2cc(C)cc(O)c2Oc2c(OC)cc(C)cc2-c2cc(C)cc(OC)c2O)c1O</smiles><smiles>COc1cc(C)ccc1O</smiles><smiles>O=C(O)CCCC(=O)OC(=O)C(=O)O</smiles><smiles>CC(CC(=O)O)C(=O)O</smiles>

4.04<smiles></smiles>

4.05<smiles>O=C(O)CC(O)C(=O)O</smiles>

4.06<smiles>COc1cc(C(=O)O)ccc1O</smiles>

4.07<smiles>COc1cc(CC(CC(C)=O)C(=O)O)ccc1O</smiles><smiles>COC1=CC(C)(c2cc(C)cc(OC)c2OC)C=C1O</smiles>

4.09<smiles>COc1cc(C)cc(Cc2cc(C)cc(OC)c2O)c1O</smiles>

5<smiles>CC(CC(=O)O)C(=O)O</smiles>

5.01

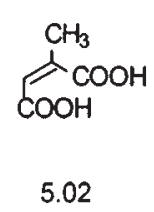<smiles>COc1cc(C)cc(Cc2cc(C)cc(O)c2O)c1O</smiles>

5.03<smiles>COc1cc(C)cc(CC(CC(C)=O)C(=O)O)c1O</smiles>

5.04<smiles>COc1cc(C)cc(CC2=CC(C)(CC(=O)O)OC2=O)c1O</smiles><smiles>COc1cc(C)cc(CC2=CC(C)(C(O)C(=O)O)OC2=O)c1O</smiles> 
Fig. 3. The amounts of oxalic acid formed during the reaction of alkaline hydrogen peroxide with three Kraft lignin model compounds in the presence and absence of various metal ions.

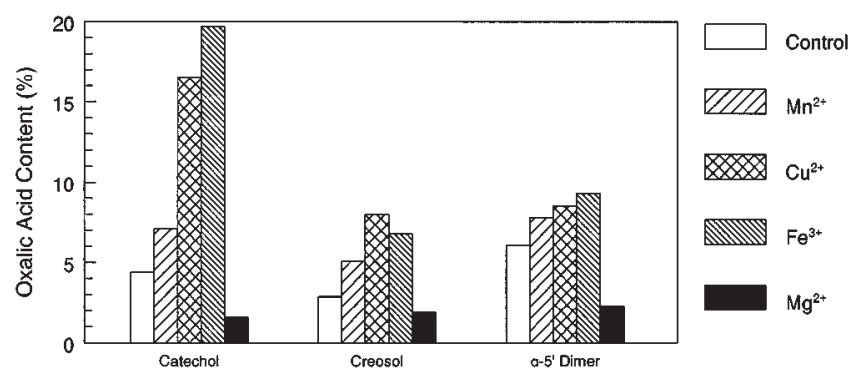

Products 2.05, 2.07, and 2.09 show the occurrence of demethoxylation reactions. These are significant reactions, since free phenolic hydroxyl groups predispose the structure of lignin to further oxidation. The sum of product 2.05, 2.07, and 2.09 shows the scale of demethoxylation reaction; product 2.05 is likely the precursor of products 2.07 and 2.09. The sum of 2.05, 2.07, and 2.09 shows that demethoxylation reactions prevail in the presence of transition metal complexes. Hydroxyl radicals forming from the decomposition of hydrogen peroxide are known to induce demethoxylation $(14,40)$. Copper ions caused the greatest degree of demethoxylation, while the presence of magnesium ions significantly suppressed demethoxylation reactions, bringing them to levels lower than those of the control experiments.

During the 60's, Kartzl's team $(30,44)$ investigated the fundamentals of the interaction of oxygen with phenols under delignification conditions. Their research efforts, amongst others, led to a comprehensive qualitative understanding of radical coupling reactions that cause the formation of biphenolic structures and their eventual degradation to 1methyl-3-methoxy-4-hydroxy benzoic acid, acetone, and carbon dioxide. Since the underlying chemistry of oxygen and peroxide delignification stages are similar, it was not surprising to discover that the dominant degradation product arising from the interaction of alkaline hydrogen peroxide with the biphenolic 5-5' dimer was 1-methyl-3-methoxy-4hydroxy benzoic acid (compound 3.04, Table 2). Residual traces of the corresponding aldehyde (compound 3.03) were also apparent in some cases, signifying that the aldehyde is the precursor to the acid during the oxidation. The small amounts of the aldehyde also signified that the oxidation of aldehyde 3.03 to acid 3.04 is a very rapid reaction under alkaline peroxide delignification conditions.

Since it is conceivable that the radical coupling product 2.06 (which is model compound 3) would convert to acid 3.04 and traces of aldehyde 3.03 , it is interesting to note that no 1-methyl-3-methoxy-4-hydroxy benzoic acid (3.04) was detected amongst the degradation products of compound 2. This may indicate that under alkaline peroxide delignification conditions the formation of radical coupling products is faster than their further degradation. The precise determination of the energies of activation for these reactions may further substantiate such a conclusion.

Amongst the three dimers examined, the $\alpha-5^{\prime}$ dimer 4 was found to be the most reactive followed by dimer $\mathbf{5}$, as evidenced by the amount of remaining starting materials after the reaction (Fig. 1a). This is not surprising when one con- siders that these compounds contain a benzylic carbon which is known to be relatively labile. That the $\alpha-5^{\prime}$ dimer 4 was slightly more reactive than dimer $\mathbf{5}$ may be explained on the basis of spin density considerations, taking into account the stability of the resulting radicals after cleavage at the benzylic centre. It is also worth noting that compound 4 yielded the rearrangement product 4.09 (Scheme 1), which is formed by the coupling of a phenoxy and a benzyl radical followed by rearomatization. Similar reaction products were found by Gierer et al. (40) when they treated creosol with hydroxyl radicals. The presence of lactonic acids 5.05, 5.06, amongst the degradation products of model $\mathbf{5}$, provides evidence that the muconic acid pathway was also operational. This pathway involves the initial formation of catechols possibly via an initial, radically induced, demethylation reaction followed by their oxidation to ortho-quinones. Such moieties may then be attacked by hydroperoxide anions, forming dioxetanes, followed by carbon-carbon bond scission of the dioxetane ring, giving rise to the corresponding carbonylcontaining fragments (15). Structures of similar nature were also present amongst the degradation products of dimers 3 and 4 , i.e., products 3.05 and 4.08 .

\section{Concluding remarks}

(i) Transition metals have the positive effects of accelerating the total degree of reaction and the demethoxylation reactions. They also have the negative effects of increasing the rate of radical coupling reactions, which can affect the further bleachability of pulp, and significantly increasing the amount of oxalic acid generated by peroxide bleaching reactions. (ii) Magnesium ions have exactly the opposite effects probably because of the deactivation of the small quantities of transition metals present in even control samples. (iii) Oxygen and peroxide delignification reactions are very similar. (iv) The order of reactivity of the phenolic lignin models towards hydrogen peroxide was determined by the degree of activation of the aromatic ring by the various ring substituents. The presence of metal ion did not alter this reactivity order. ( $v)$ The addition of metal ions induced the formation of radical species by initiating the decomposition of hydrogen peroxide to radicals and (or) catalyzing the formation of phenoxy radical directly. In this work, the overall catalytic ability of the transition metals toward increasing the reactivity of phenolic models was found mostly to be $\mathrm{Mn}^{2+}>\mathrm{Cu}^{2+}$ $>\mathrm{Fe}^{3+}$, which is the same as the order of activity toward peroxide decomposition.

\section{Acknowledgements}

The authors would like to acknowledge Mr. Luc Lapierre of Paprican for his input while reviewing the manuscript. This research was supported by the Government of Canada in the form of a Strategic Grant.

\section{References}

1. G. Gellerstedt and I. Pettersson. J. Wood Chem. Technol. 2(3), 231 (1982).

2. G.C. Hobbs and I. Abbot. J. Wood Chem. Technol. 11(2), 225 (1991).

3. C.W. Dence and S. Omori. TAPPI, 69(9), 120 (1986). 
4. W.G. Strunk. In Pulp and paper manufacture. Mechanical pulping. Vol. 2. Edited by R.A. Leask. 1987. p. 238.

5. J. Gierer, K. Jansbo, and T. Reitberger. J. Wood Chem. Technol. 13(4), 561 (1993).

6. J. Abbot. J. Pulp Paper Sci. 17(1), J10 (1991).

7. J. Abbot and D.G. Brown. Can. J. Chem. 68, 1537 (1990).

8. R.H. Reeves and I.A. Pearl. TAPPI, 48(2), 121 (1965).

9. C.W. Bailey and C.W. Dence. TAPPI, 52(3), 491 (1969).

10. A.W. Kempf and C.W.Dence. TAPPI, 58(6), 104 (1975).

11. R. Agnemo and G. Gellerstedt. Acta Chem. Scand. B33, 337 (1979).

12. G. Gellerstedt and R. Agnemo. Acta Chem. Scand. B34, 275 (1980).

13. S. Omori and C.W. Dence. Wood Sci. Technol. 15, 113 (1981).

14. A.J. Nonni and C.W. Dence. Holzforschung, 42(1), 37 (1988).

15. J. Gierer and F. Imsgard. Svensk Papperstidn. 80(16), 510 (1977).

16. D.G. Brown and J. Abbot. J. Wood Chem. Technol. 15(1), 85 (1995).

17. U. Germgard and S. Nordén. Int. Pulp Bleaching Conf. TAPPI Proc. 1994. p. 53.

18. B. Stromberg and R. Szopinski. Int. Pulp Bleaching Conf. TAPPI Proc. 1994. p. 199.

19. B.P. Roy, B. Van Lierop, and A. Audet. TAPPI Pulp. Conf. Proc. 1995. p. 771.

20. B. Van Lierop, B.P. Roy, R. Berry, A. Audet and L. Shackford. Int. Pulp Bleaching Conf. TAPPI Proc. 1996. p. 303.

21. T. Eriksson and J. Gierer. J. Wood Chem. Technol. 5(1), 53 (1985).

22. A. Granata and D.S. Argyropoulos. J. Agric. Food Chem. 43(6), 1538 (1995).

23. B. Ahvazi, G. Pageau, and D.S. Argyropoulos. Can. J. Chem. 76, 506 (1998).

24. F.X. Douglas, W. Reeve, and A.B. McKague. J. Wood Chem. Technol. 16(1), 35 (1996).

25. K. Kratzl and F.W. Virhopper. Monatsh. Chem. 102, 425 (1971).

26. J.T. Scanlon and D.E. Willis. J. Chrom. Sci. 23, 333 (1985).

27. W.A. Dietz. J. Gas Chrom. 68 (1967).

28. R.C. Francis and W.D. Reeve. J. Pulp Paper Sci. 13(6), 171 (1987).

29. E. Johansson and S. Ljunggren. J. Wood Chem. Technol. 14(4), 507 (1994).

30. K. Kratzl, P. Claus, W. Lonsky, and J.S. Gratzl. Wood Sci. Technol. 8, 35 (1974).
31. J. Gierer. Holzforschung, 51, 34 (1997).

32. J.L. Colodette, S. Rothenberg, and C.W. Dence. J. Pulp Paper Sci. 15(2), J45 (1989).

33. P.K. Smith and T.J. McDonough. Svensk Papperstid. 12, R106 (1985).

34. L.L. Landucci. Trans. Tech. Sect. Can. Pulp. Pap. Assoc. 4, 25 (1978).

35. J. Basta, L. Holtinger, and J. Hook. 6th Int. Symp. Wood Pulping Chem. 237 (1991)

36. M. Yasumoto, Y. Matsunoto, and A. Ishizu. J. Wood Chem. Technol. 16(1), 95 (1996).

37. H.S. Isbell, E.W. Parks, and R.G. Naves. Carbohydr. Res. 45 , 197 (1975)

38. R.C. Francis. TAPPI Press Anthol. 418 (1989).

39. J.W. Weaver, L.R. Schroeder, and N.S. Thompson. Pap. Puu. 1, 31 (1979).

40. L. Gierer, E. Yang, and T. Reitberger. Holzforschung, 46(6), 495 (1992).

41. K.R. Kumar, C. Jacobs, H. Jameel, and H.-M.Chang. Int. Pulp Bleaching Conf. TAPPI Proc. 147 (1996).

42 Y. Sun and D.S. Argyropoulos. Holzforschung, 50(2), 175 (1996).

43. M. Holocher-Ertl, P. Fricko, and K. Kratzl. SPCI Int Symp. Wood Pulp. Chem. Vol. 2. Preprints, Stockholm. June, 1981. pp. 83-89.

44. K. Kratzl, J. Gratzl, and P. Claus. Adv. Chem. Ser. 59, 157 (1966).

\section{Appendix}

Contributions to the effective carbon number.

\begin{tabular}{lll}
\hline Atom & Type & ECN contribution \\
\hline $\mathrm{C}$ & Aliphatic & 1 \\
$\mathrm{C}$ & Aromatic & 1 \\
$\mathrm{C}$ & Olefinic & 0.95 \\
$\mathrm{C}$ & Acetylenic & 1.3 \\
$\mathrm{C}$ & Carbonyl & 0 \\
$\mathrm{C}$ & Carboxyl & 0 \\
$\mathrm{C}$ & Ether & -1 \\
$\mathrm{C}$ & Primary alcohol & -0.5 \\
$\mathrm{C}$ & Secondary alcohol & -0.75 \\
TMS-derivatives: & & \\
H-C-O-TMS & & 3.70 \\
CO $_{2}$-TMS & & 3.0 \\
\hline
\end{tabular}

